\title{
TEACHERS' PERCEPTIONS ON WOMEN IN STEM: BREAKING THE STEREOTYPES
}

Lili Zhou, Graduate Student, Purdue University, zhou756@purdue.edu

Alankrita Chhikara, Graduate Student, Purdue University, achhikar@purdue.edu

Stephanie Oudghiri, Clinical Assistant Professor, Purdue University, stoudghi@ purdue.edu

Araba A. Z. Osei-Tutu, Limited Term Lecturer, Purdue University, aoseitut@ purdue.edu

Razak Dwomoh, Graduate Student, Purdue University, rdwomoh@purdue.edu

\begin{abstract}
We designed and offered a Professional Development (PD) course for K-12 in-service teachers and educators across Indiana to address critical theory on race, immigration, English Language Learners (ELLs), and gender. In this study, we investigate teachers' perceptions on gender stereotypes in STEM from the PD course. We report findings from the analysis of participants' responses from pre-course surveys and posed discussions during the course.
\end{abstract}

\section{Theoretical Perspectives}

Underlying negative messages of females' inferior abilities of mathematics and science continue to influence assumptions about girls and STEM careers. The reviewed literature informs us that teachers' perceptions of gender stereotypes in STEM fields have an impact on students' stereotypes of gender and STEM, self-efficacy in STEM learning, and STEM career interests. The culture of the classroom, discourse, and learning environments the teacher creates would be a space for students to interrupt stereotypes or continue to communicate stereotypes. A supportive learning environment demonstrates care about the girls' needs, recognizes their contributions, and offers opportunities for recognition and development (Belenky et al., 1986). Using inclusive and non-discriminative pedagogies could improve equity and value girls' voices (Anderson, 2005).

\section{Methods and Findings}

The data for the study includes 158 survey entries which were collected at the beginning of the course and 67 posts on discussion boards. The research team, first individually and then collectively, analyzed all data sources through thematic analysis to identify common themes.

Teachers provided evidence from their personal and classroom teaching experiences that illustrate the existence of stereotypes in K-12 education, which permeate to the society, norms in classroom, and curricula. Teachers noticed that girls and women have different ways of knowing from their own teaching and learning experiences. In addition, teachers proposed multiple ways to address gender stereotypes in teaching, including integrating role models into curriculum, developing growth mindset, and promoting a justice-oriented classroom discourse.

\section{References}

Anderson, D. L. (2005). A portrait of a feminist mathematics classroom: What adolescent girls say about mathematics, themselves, and their experiences in a "unique" learning environment. Feminist Teacher, 15(3), 175-194. http://www.jstor.org/stable/40546037

Belenky, M. F., Clinchy, B. M., Goldberger, N. R., \& Tarule, J. M. (1986). Women's ways of knowing: The development of self, voice, and mind (Vol. 15). Basic Books. 